NASA/TM-2006-214130

\title{
Conceptual Design of a Condensing Heat Exchanger for Space Systems Using Porous Media
}

Mohammad M. Hasan

Glenn Research Center, Cleveland, Ohio

Lutful I. Khan

Cleveland State University, Cleveland, Ohio

Vedha Nayagam and Ramaswamy Balasubramaniam

National Center for Space Exploration Research, Cleveland, Ohio 


\section{NASA STI Program . . . in Profile}

Since its founding, NASA has been dedicated to the advancement of aeronautics and space science. The NASA Scientific and Technical Information (STI) program plays a key part in helping NASA maintain this important role.

The NASA STI Program operates under the auspices of the Agency Chief Information Officer. It collects, organizes, provides for archiving, and disseminates NASA's STI. The NASA STI program provides access to the NASA Aeronautics and Space Database and its public interface, the NASA Technical Reports Server, thus providing one of the largest collections of aeronautical and space science STI in the world. Results are published in both non-NASA channels and by NASA in the NASA STI Report Series, which includes the following report types:

- TECHNICAL PUBLICATION. Reports of completed research or a major significant phase of research that present the results of NASA programs and include extensive data or theoretical analysis. Includes compilations of significant scientific and technical data and information deemed to be of continuing reference value. NASA counterpart of peer-reviewed formal professional papers but has less stringent limitations on manuscript length and extent of graphic presentations.

- TECHNICAL MEMORANDUM. Scientific and technical findings that are preliminary or of specialized interest, e.g., quick release reports, working papers, and bibliographies that contain minimal annotation. Does not contain extensive analysis.

- CONTRACTOR REPORT. Scientific and technical findings by NASA-sponsored contractors and grantees.
- CONFERENCE PUBLICATION. Collected papers from scientific and technical conferences, symposia, seminars, or other meetings sponsored or cosponsored by NASA.

- SPECIAL PUBLICATION. Scientific, technical, or historical information from NASA programs, projects, and missions, often concerned with subjects having substantial public interest.

- TECHNICAL TRANSLATION. Englishlanguage translations of foreign scientific and technical material pertinent to NASA's mission.

Specialized services also include creating custom thesauri, building customized databases, organizing and publishing research results.

For more information about the NASA STI program, see the following:

- Access the NASA STI program home page at http://www.sti.nasa.gov

- E-mail your question via the Internet to help@sti.nasa.gov

- Fax your question to the NASA STI Help Desk at 301-621-0134

- Telephone the NASA STI Help Desk at 301-621-0390

- Write to:

NASA STI Help Desk

NASA Center for AeroSpace Information 7121 Standard Drive Hanover, MD 21076-1320 
NASA/TM-2006-214130

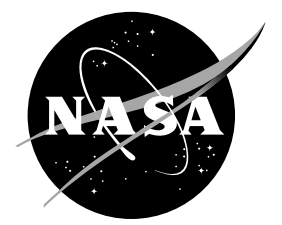

\section{Conceptual Design of a Condensing Heat Exchanger for Space Systems Using Porous Media}

Mohammad M. Hasan

Glenn Research Center, Cleveland, Ohio

Lutful I. Khan

Cleveland State University, Cleveland, Ohio

Vedha Nayagam and Ramaswamy Balasubramaniam

National Center for Space Exploration Research, Cleveland, Ohio

Prepared for the

35th International Conference on Environmental Systems (ICES)

cosponsored by the SAE, AIAA, AIChE, ASME, and the International ICES Committee

Rome, Italy, July 11-14, 2005

National Aeronautics and

Space Administration

Glenn Research Center

Cleveland, Ohio 44135 


\section{Acknowledgments}

The authors are greatful to D. Westheimer, S. Lee, and G. Tuan, NASA Johnson Space Center, and N. Daidzic, National Center for Microgravity Research for their generous sharing of information on many aspects of this project. We also acknowledge the help from M.P. Doherty and D. Truong from NASA Glenn Research Center and the engineering team from the Zin Technologies.

Level of Review: This material has been technically reviewed by technical management.

Available from

NASA Center for Aerospace Information 7121 Standard Drive

Hanover, MD 21076-1320
National Technical Information Service 5285 Port Royal Road Springfield, VA 22161

Available electronically at http://gltrs.grc.nasa.gov 


\title{
Conceptual Design of a Condensing Heat Exchanger for Space Systems Using Porous Media
}

\author{
Mohammad M. Hasan \\ National Aeronautics and Space Administration \\ Glenn Research Center \\ Cleveland, Ohio 44135 \\ Lutful I. Khan \\ Cleveland State University \\ Cleveland, Ohio 44115 \\ Vedha Nayagam and Ramaswamy Balasubramaniam
National Center for Space Exploration Research
Glenn Research Center
Cleveland, Ohio 44135
}

\begin{abstract}
Condensing heat exchangers are used in many space applications in the thermal and humidity control systems. In the International Space Station (ISS), humidity control is achieved by using a water cooled fin surface over which the moist air condenses, followed by "slurper bars" that take in both the condensate and air into a rotary separator and separates the water from air. The use of a cooled porous substrate as the condensing surface provides an attractive alternative that combines both heat removal as well as liquid/gas separation into a single unit. By selecting the pore sizes of the porous substrate a gravity independent operation may also be possible with this concept. Condensation of vapor into and on the porous surface from the flowing air and the removal of condensate from the porous substrate are the critical processes involved in the proposed concept. This paper describes some preliminary results of the proposed condensate withdrawal process and discusses the on-going design and development work of a porous media based condensing heat exchanger at the NASA Glenn Research Center in collaboration with NASA Johnson Space Center.
\end{abstract}

\section{INTRODUCTION}

Condensing heat exchangers ( $\mathrm{CHX}$ ) have been used for thermal and humidity control in every manned space flight system launched by the United States [1]. The control of temperature and humidity within a spacecraft requires removal of both sensible heat generated by power consuming equipment and humans, and water vapor primarily generated by evaporation from humans. A CHX is designed to accomplish both of these functions. The current system for control and humidity removal for the space shuttle and International Space
Station (ISS) utilizes a two- stage process. First, moisture is condensed onto the fins of a plate-fin heat exchanger which is then forced through the "slurper bars" by the air flow. The slurper bars take in a twophase mixture of air and water that is then separated by a rotary separator. A drawing of the key components of the ISS condensing heat exchanger is shown in Figure 1 [2]. A brief description of this system can also be found in Ref. [3].

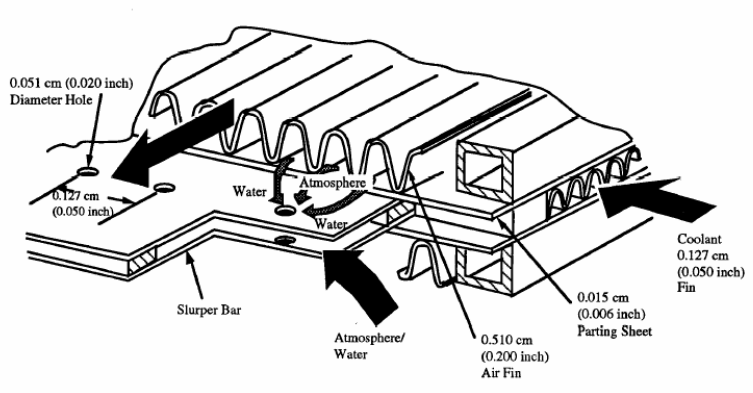

Figure 1. Illustration of the ISS Condensing Heat Exchanger.

A more efficient design of a $\mathrm{CHX}$ would condense and remove the water directly from the air stream without the need for an additional water separator downstream. In this paper we describe one such design that utilizes capillary forces to collect and remove water and is capable of operating in varying gravitational conditions including microgravity, Lunar and Martian gravity. The concept involves the use of a porous substrate with high thermal conductivity as the cold surface over which condensation occurs and liquid collects. The condensed water is then removed by an embedded porous media connected to a suction device. The thermal properties, the porosity and the wetting characteristics of the porous materials are judiciously chosen so that efficient 
condensation is promoted and at the same time air penetration into the suction lines is avoided.

Before this heat exchanger concept can be used to design a humidity/thermal control system in an actual space mission several critical issues concerning the physical processes need to be resolved. The physical processes include heat and mass transfer rates, flow characteristics through unsaturated porous media in varying gravitational fields, and operational procedures including shut-down and start-up transients. A test bed that is capable of providing a conditioned moist air stream over a wide range of conditions anticipated in future space missions is being built at NASA Glenn Research Center. In this facility the test section along with the $\mathrm{CHX}$ can be rotated with respect to the gravity vector to simulate in a simple way the effects of varying gravity on the performance of the system. The $\mathrm{CHX}$ and the test-bed are instrumented to acquire the relevant information during the experiments. The data from these experiments are used to develop empirical correlations for heat and mass transfer and to validate theoretical and numerical modeling studies currently underway. Space-based flight experiments are also planned for the future to evaluate the performance of the condensing heat exchanger in a long duration microgravity environment.

It is anticipated that the porous media based condensing heat exchanger will provide a robust, lightweight passive condenser and liquid separator and it will be operationally simple. It applies to ISS and all advanced manned missions, a lunar habitat, Mars habitat and Mars transit vehicle for temperature and humidity control as well as separation of water from a mixture of water vapor and gases in in-situ resource utilization (ISRU) applications.

\section{CONDENSING HEAT EXCHANGER CONCEPT}

A schematic illustration of a specific design concept is shown in Figure 2. The system consists of a porous substrate with embedded porous tubes placed at regular intervals and connected to a suction device via a header assembly. The porous substrate also contains cooling copper tubes through which chilled water is circulated.

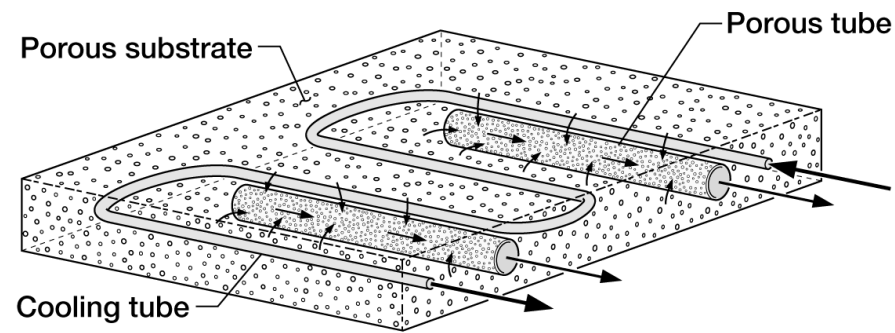

Figure 2. Composite porous media condensing heat exchanger concept.

Condensation of moist air occurs inside and over the porous substrate when it is cooled below the dew point.
The porous plate absorbs the condensate by capillary action and the accumulated water within the porous plate is selectively removed by the embedded porous tubes. Air penetration into the porous tubes is avoided by selecting tubes with a higher bubble pressure relative to the porous substrate. The porous tubes must be operated under a suction-head below its bubble pressure. However, care should be exercised to avoid bubble evolution from dissolved gases due to excessive lowering of pressure. This concept is illustrated in Fig. 3.

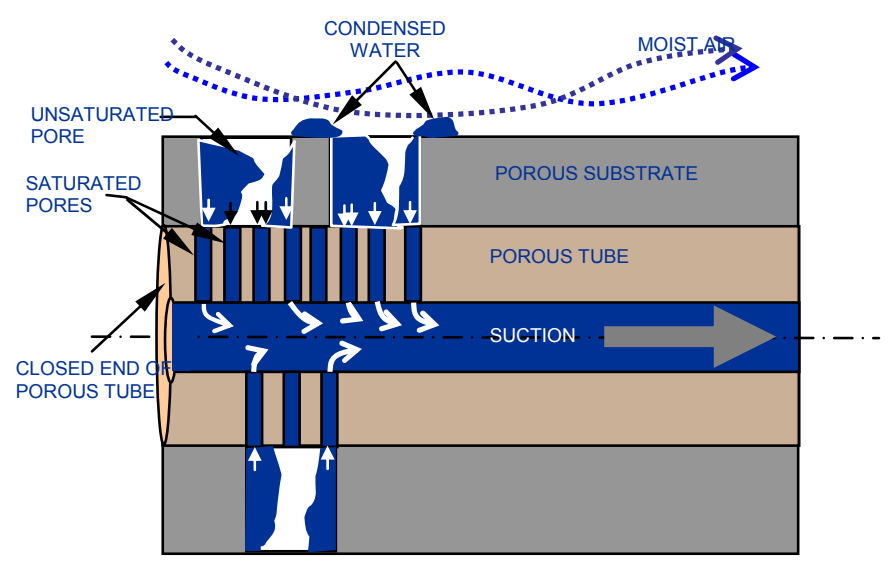

Figure 3. Porous substrate and condensate removal tubes with different pore sizes (not to scale).

\section{PHYSICAL PROCESSES}

The heat and mass transport phenomena of moisture condensation over cooled substrates and the hydrodynamics of air/water flow in porous media are reasonably well understood [4]. However, the unique geometrical configuration of the heat exchanger and the need for it to operate in varying gravity field including microgravity pose new challenges. In the following we examine some of the key physical processes mainly to prove the feasibility of the proposed concept.

CONDENSATION HEAT TRANSFER - The rate of condensation of vapor into and over the surface of the chilled porous substrate from the flowing moist air depends on the temperature gradient inside the porous media, flow through the saturated or unsaturated porous substrate, and the velocity, temperature and the dew point of the air stream. The rate of heat removal capacity per unit area, $Q$, of the porous plate for steady state condition may be estimated by

$$
Q=\frac{T_{d}-T_{c}}{\delta / k_{e}+\delta_{w} / k_{w}}
$$

Where, $T_{d}$ and $T_{c}$ are the dew point temperature and the centerline temperature of the plate, respectively. It is assumed that a thin condensate (water) film of thickness, $\delta_{w}$ is formed on the surface. The thickness of 
the porous plate is $\delta$ and $k_{e}$ and $k_{w}$ are the thermal conductivities of the substrate and the condensate. The temperature profiles in the liquid film and in the porous substrate of thickness, $\delta$ are approximately linear. The heat flux, $Q$ includes both the sensible heat and the heat of condensation. Theoretical solutions of the conjugate heat and mass transfer with condensation including porous substrate are being performed and will be reported elsewhere [5]. This analysis shows that

$$
P e_{\delta w}=\ln \left[\left(1+\frac{J a_{g}}{\omega}+J a_{w}\right) /\left(1+\frac{J a_{g}}{\omega}\right)\right]
$$

where $P e_{\delta w}$ is the Peclet number based on $\delta_{w}$ and the velocity in the porous substrate, $\omega$ is the humidity ratio, and $J a_{g}$ and $J a_{w}$ are the Jacob numbers in the air stream and the water film. We postulate that if the porous plate remains unsaturated to a certain degree the formation of the liquid film may be avoided or its thickness can be greatly reduced due to imbibition of condensate into the porous plate. This enhances the heat removal capacity and eliminates or reduces the liquid carry-over with the flowing air stream.

CONDENSATE RETENTION IN THE POROUS SUBSTRATE - The capillary pores of a porous media, when hydrophilic, develops capillary suction pressure $P_{c}$ given by

$$
P_{c}=\frac{2 \sigma}{r} \cos \theta
$$

where, $\sigma$ is the surface tension of the liquid to air and $\theta$ is the contact angle of water with the porous solid. The contact angle depends on the hydrophilic characteristics of the pore. A hydrophilic porous plate can effectively absorb and retain any liquid that comes in contact with its surface by its capillary pressure. The process would be equally effective in terrestrial and microgravity conditions. However, the capillary pressure of the pores diminishes with increasing degree of saturation. Therefore, the porous substrate would lose its liquid trapping capacity with increasing degree of saturation.

Once the saturation of the porous substrates reaches a certain level, water may be selectively extracted through the porous tubes by applying suction. This would reduce the degree of saturation of the porous substrate and restore the capillary suction.

SELECTIVE WATER REMOVAL BY SATURATED POROUS TUBES- For hydrophilic pores filled with water (wetting phase), a pressure equal to $P_{c}$ is required to displace the water from the pores with air (non-wetting phase). This pressure corresponds to the 'bubble pressure'. As long as the external pressure is below the bubble pressure, air cannot migrate through the pores while water is transmitted freely. Consequently, the porous media demonstrates selective permeability to the wetting phase. It is therefore possible to design a system for phase separation using a hydrophilic porous media. Because capillary pressure is not gravity dependent, a system so designed would be equally effective in terrestrial and microgravity conditions. Design of selective liquid separation by the embedded porous media is based on this concept.

WATER EXTRACTION FROM UNSATURATED POROUS MEDIA-The flow in an unsaturated porous media may be given by the Richard equation:

$$
q=-K(w)-K(w)\left(-\frac{\partial h_{c}}{\partial w}\right) \frac{\partial w}{\partial z}
$$

where, $w$ is the volumetric water content, $h_{c}$ is the suction potential, and $K(w)$ is the unsaturated hydraulic conductivity which depends on, among other things, the saturation of the pores and capillary suction corresponding to the degree of saturation. No universal law is available for correlating the unsaturated hydraulic conductivity with the volumetric water content and capillary suction. However, several empirical correlations and models exist for natural stones and granular materials. As an example, a simple empirical correlation suggested by Brooks and Corey [6] is considered:

$$
K(w)=K_{s a t} S^{d}
$$

$K_{\text {sat }}$ is the effective hydraulic conductivity at fully saturated condition, $S$ is the effective degree of saturation and $d$ is a constant dependent on the pore size distribution and typically varies in the range of 3 to 4. Brooks and Corey [6] suggested $d=4$ for rocks. Equation (5) shows that the unsaturated hydraulic conductivity reduces sharply as the degree of saturation reduces. This trend is expected during the water removal process from the external porous media (plate). Furthermore, the microgravity effects on the variation of hydraulic conductivity in unsaturated porous media are not well understood [7]. The implication of this behavior is that the water removal flow-rate will fluctuate significantly with the saturation state of the plate.

\section{GROUND-BASED EXPERIMENTS}

A successful demonstration of selective liquid extraction by a composite porous system is critical to the proposed concept. The following sections give an account of fabrication of a full-scale test module and some preliminary results of a bench scale setup.

FULL-SCALE MODULE- We have fabricated flat-plate heat exchangers using sintered porous bronze and graphite as the substrate materials. We have also 
chosen porous ceramic tubes for the condensate withdrawal system. The graphite substrate (PG-45 National Electrical Carbon Products) had a porosity of $48 \%$ and an average pore size of 0.0023 inch. This particular graphite is chosen to obtain a "bubble pressure" of around 1 psia. The porous ceramic tubes had an average pore size of $6.7 \times 10^{-5}$ inch to give a "bubble pressure" of approximately 14.7 psia. A simple flat-plate configuration was chosen for the condensing substrate geometry so that experimental results can be compared against analytical models of the problem. Full-scale tests using these condensing heat exchangers are currently underway in a test-bed at the NASA GRC. A drawing of the heat exchanger assembled inside the test-section of the test-bed is shown in Figure 4.

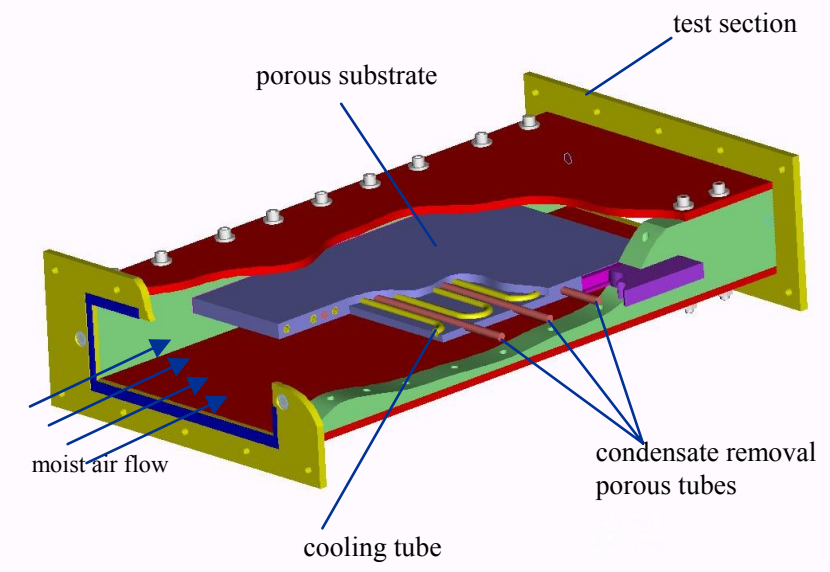

Figure 4. Flat-plate graphite condensing heat exchanger shown installed in the test-section.

BENCH SCALE TESTS-Besides the full-scale tests we have carried out a number of bench-top tests to verify the feasibility of the proposed heat exchanger concept. The results from these tests are described below. An experimental setup was constructed with a graphite block as the external porous substrate and ceramic porous tubes as the internal water-retrieving unit. The graphite block was $15 \times 20 \times 4.6 \mathrm{~cm}$ in dimension with three $1.08 \mathrm{~cm}$ diameter, $7.6 \mathrm{~cm}$ deep holes to accommodate the $1 \mathrm{~cm}$ diameter porous tubes (see, Fig.5). The graphite bloc bubble pressure was about 0.7 psi (assuming theta $=0 \mathrm{deg}$ ), and the bubble pressure of the ceramic tubes was about $14.7 \mathrm{psi}$. The low bubble pressure of the graphite block was chosen to minimize resistance of water flow under unsaturated conditions. The graphite block had very high hydraulic conductivity of $1.47 \times 10^{-2} \mathrm{~cm} / \mathrm{s}$ compared to that of the porous tubes $\left(7.56 \times 10^{-7} \mathrm{~cm} / \mathrm{s}\right)$.

A schematic diagram of this experimental setup is shown in Figure 5. The range of suction pressure, $\Delta P$ was chosen between 3.5 and 7 psi. The upper limit of $\Delta \mathrm{P}$ was selected to minimize the evolution of dissolved gases from the liquid phase. The pressure was controlled by a proportional solenoid valve (Clippard Minimatics) and measured by a differential pressure transducer (Sensotec Model FDW Range 15psid). The extraction of the liquid from the graphite block was initiated at a known degree of saturation. The porous tubes primed to complete saturation were inserted into the graphite block and subjected to a desired suction pressure $\Delta P$. The suction pressure was applied with a Drummund vacuum pump. Pressure and water outflow were recorded at different time intervals.

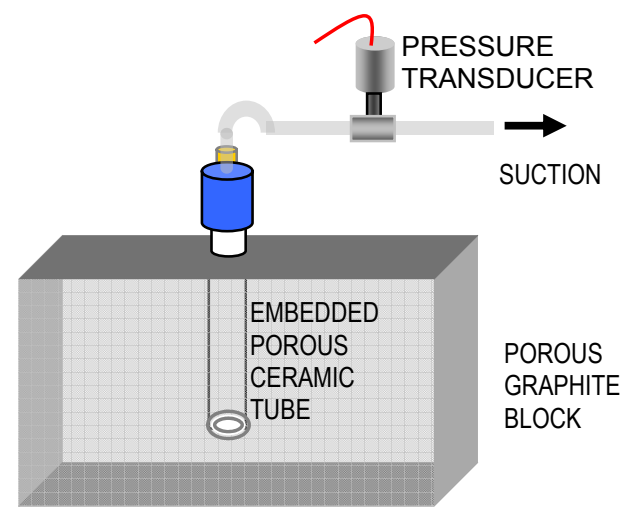

Figure 5. Schematic illustration of the bench-top test apparatus.

CERAMIC TUBE CHARACTERIZATION-The ceramic tubes are selectively permeable to water only under fully saturated conditions. In practice, however, complete saturation is difficult to attain. It was therefore necessary to evaluate if the porous tubes could function as a selectively permeable medium under moderate saturation, which involved immersion in water and pumping under a small suction pressure (about 3 psi).

The results of this experiment are shown in Figure 6 . The test involves flow rate investigation in a ceramic tube at different submergence levels. The ceramic tube was first saturated by immersion in water and suction (3.5 psi) for about 10 minutes. It was then subjected to $\Delta \mathrm{P}=3.5$ psi suction while the submergence in water was gradually reduced from $90 \%$ to $0 \%$. The tube selectively extracted water even though a part was exposed to air. No significant gas bubbles were observed at any time during the experiment. The results indicate that the porous tube could be saturated to a satisfactory level with very little effort. The calculated flow rate in the tube is also shown for comparison.

It should be kept in mind that as the pressure is reduced from the liquid-gas interface, the partial pressure of the dissolved gases in the water reduces. This would release dissolved gases from the aqueous phase producing bubbles. Henry's Law gives the equilibrium between the concentration of a gas $C_{a}$ in the aqueous phase and its partial pressure $P_{g}$ in the gas phase:

$$
C_{a}=k_{H} P_{g}
$$


Where $k_{H}$ is the Henry's constant. The values of $k_{H}$ for predominant gases in air, oxygen and nitrogen, are 1.3E-3 M/atm and 6.5E-4 M/atm respectively. If the pressure is reduced from $14.7 \mathrm{psi}$ to $11.2 \mathrm{psi}(\Delta \mathrm{P}=3.5$ psi), about $24 \%$ of the gases will come out of the solution according to equation (6). Assuming the volume of a gas as $22.4 \mathrm{~L} /$ mole at STP, the total volume of expelled gas would be about $5.5 \mathrm{cc}$ per liter of water. In the experimental setup, the volume of water subjected to the $11.2 \mathrm{psi}$ pressure was about $100 \mathrm{cc}$. This translates into about $0.55 \mathrm{cc}$ of degassing during the suction.

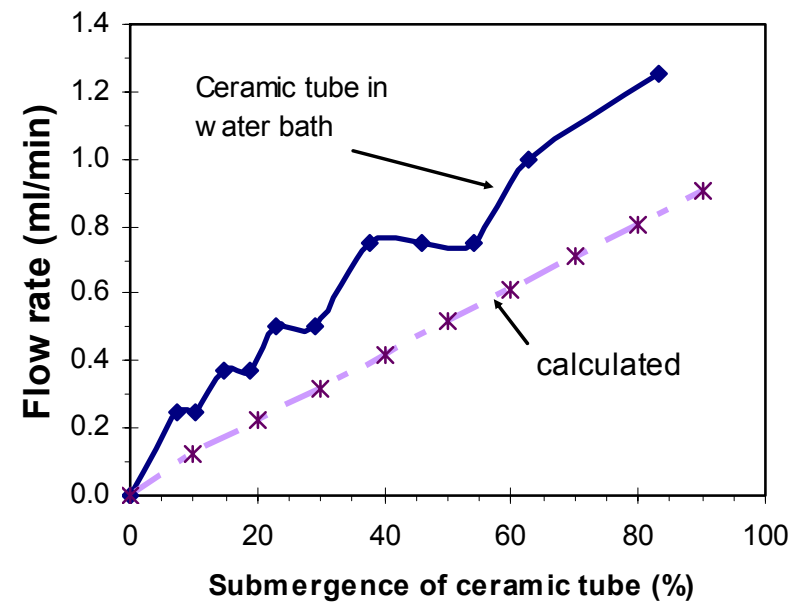

Figure 6 . Selective removal of water by a ceramic tube submerged in water.

POROUS PLATE CHARACTERIZATION-The extraction of water from a porous media under unsaturated condition is dependent on the pore-size distribution, pore tortuosity, and the capillary pressure of the pores at various saturation conditions. The pressure-saturation curve of the graphite block material is shown in Figure 7. The experimental bubble entry point is about $0.6 \mathrm{psi}$, which is in good agreement with the theoretical value. As the pressure is increased, more and more pores are emptied and the degree of saturation reduces. This correlation has an important significance in choosing the operating suction pressure for the condensate withdrawal unit. For example, if the liquid withdrawal pressure is $2 \mathrm{psi}$, the saturation of the plate cannot be reduced below about $58 \%$. Therefore, the suction should be discontinued at that point because no yield will occur. This type of plot could allow the designers to predict the volume of water that could be extracted from the condensing porous substrate.

SELECTIVE WATER EXTRACTION VERIFICATIONExperimental results of water extraction from the unsaturated graphite block under 3.5 and 7 psi suction pressures are shown in Figure 8. There was no influx of water in the graphite during the experiment. The initial saturation was about $90 \%$. As water was removed, the saturation reduced and this resulted in a drastic reduction in the flow rate. For the 7 psi suction pressure, the flow rate reduced from $3 \mathrm{ml} / \mathrm{min}$ to about 1 $\mathrm{ml} / \mathrm{min}$ for a saturation reduction of about $5 \%$. When the experiment was conducted at $3.5 \mathrm{psi}$, the flow rate reduced from $1.5 \mathrm{ml} / \mathrm{min}$ to $0.5 \mathrm{ml} / \mathrm{min}$ for the same reduction in saturation. No bubbles were observed at $3.5 \mathrm{psi}$, while some very tiny bubbles were observed in the suction tubes at $7.5 \mathrm{psi}$. However, this was not unexpected because, according to equation (6), pressure reduction by 7.5 psi would remove a considerable amount of the dissolved gases from the aqueous phase.

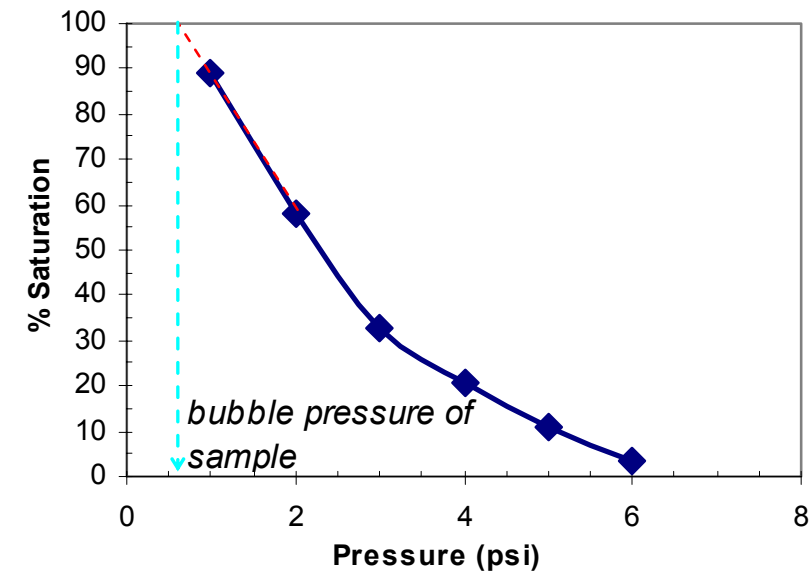

Figure 7. Pressure-saturation curve PG-45 graphite.

For a condensation rate of $1 \mathrm{lb} /$ day, the required removal rate would be about $0.31 \mathrm{ml} / \mathrm{min}$, which is less than the reduced flow rate at $\Delta \mathrm{P}=3.5 \mathrm{psi}$, horizontal. It appears that the proposed system could be designed to selectively remove water at a higher rate than the rate of moisture condensation on the porous substrate.

Flow rates at two different graphite block orientations with respect to gravity are also shown in Figure 8 . Comparison of the vertical and horizontal flow rates at 3.5 psi shows reduced flow in the graphite block for the vertical orientation. The fluid extraction in the vertical direction was against the gravity. This result gives some indication about the possible effect of gravity on the performance of the proposed $\mathrm{CHX}$. The variation of flow rates between these two orientations is likely dependant on the system geometry and is currently under investigation. The extent of dewatering of the graphite block that can be attained under a given suction head is also under study.

OPERATIONAL PROCEDURE - Based on the above discussions an operational procedure for the heat exchanger can be developed. The operation can start with the condensing substrate fully saturated or dry, but the condensate withdrawal tube must be primed to saturation. Assuming a porosity value of $n$ and a substrate volume $V$, the amount of liquid the substrate can retain is $n V$. For a volume condensation rate of $C$, 
the time for saturation will be $n V / C$ when starting from an initially dry state. For example, the time required for an 8 in X 10 in plate with 1 in thickness and $40 \%$ porosity to reach $85 \%$ saturation will be about 24 hours for a condensation rate of $1 \mathrm{lb} /$ day. At some high degree of saturation, the porous tubes will start extracting the water from the plate whose flow-rate will be a function of the saturation. Assuming that the hydraulic conductivity expressed as a function of the saturation can account for the diminishing flow-rate at reduced saturation, the system will come to a steady-state condition when the flow-rate corresponds to the rate of condensation. At this point the pump may be stopped to saturate the plate since the flow-rate becomes more efficient at higher saturation as seen from Fig.8.

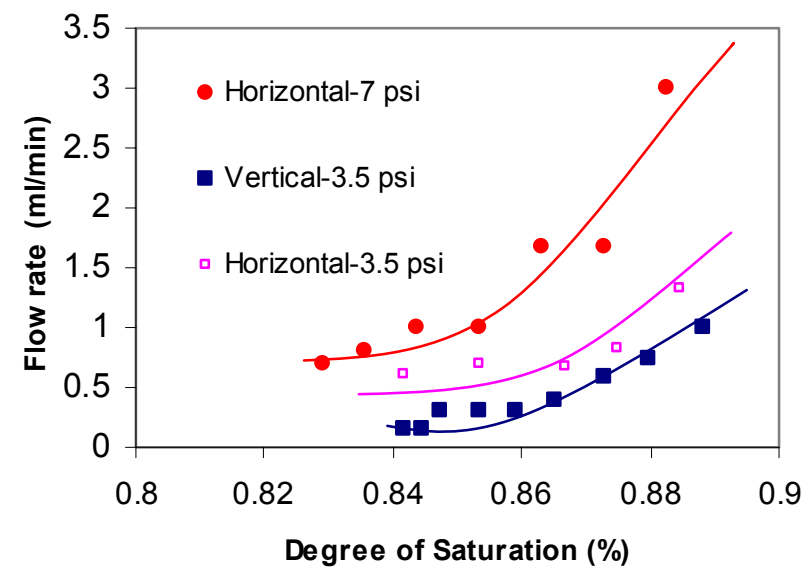

Figure 8. Selective extraction of water from an unsaturated graphite block at horizontal and vertical orientations.

\section{FUTURE WORK}

There are still a number of issues that need to be resolved before the $\mathrm{CHX}$ can be considered fully operational. One of the important unresolved issues is the ultimate geometrical configuration of the heat transfer surface. The current flat-plate geometry, though convenient for testing and interpretation of the test results using simplified theoretical models, may not be optimal in terms of efficient heat transfer. Other major issues are the performance of the $\mathrm{CHX}$ in a microgravity environment, the control of microbial growth, and long term maintainability of porous surface wettability.

\section{CONCLUSION}

A concept for the design of a condensing heat exchanger that is capable of operating under varying gravitational environments including microgravity has been proposed. The concept uses a composite porous media with two different average pore sizes and consequently two different bubble pressures. The surface over which condensation occurs has a larger pore size and collects the condensate using capillarity, and the tubes inserted into the substrate has a smaller pore size and selectively withdraws the condensate. Preliminary bench-top experiments have demonstrated the feasibility of this concept. Further work is currently underway to optimize the geometrical design of the condensing surface as well as demonstrating the function of this heat exchanger in a long duration microgravity environment.

\section{REFERENCES}

1. P. Eckart, "Spaceflight Life Support and Biospherics," Kulwer/Microcosm, 1996.

2. T. A. Ozbolt, "US Lab Architecture Control Document, Volume 7: Temperature and Humidity Control, Revision New, D683-14719-1-7," Boeing Defense and Space Group, Missile \& Space Division, Huntsville, Alabama, December 20, 1996.

3. E. K. Ungar and F. A. Ouellette, "Design of a Shuttle Air and Water Prefilter for Reduced Gravity Operation," $22^{\text {nd }}$ ICES, Seattle, WA, July 13-16, 1992, SAE 921161.

4. M. Kaviany, Principles of Heat Transfer in Porous Media, Springer-Verlag, 1991.

5. R. Balasubramaiam, V. Nayagam, L. Khan, and M. M. Hasan, "Analysis of heat and mass transfer during condensation over a porous substrate," (submitted) Interdisciplinary Transport Phenomena in Microgravity and Space Sciences IV Conference, Tomar, Portugal, August 2005.

6. R. H. Brooks and A. T. Corey, "Properties of porous media affecting fluid flow," J. Irrig. Drain. Div., Am. Soc. Civil Eng., Vol. 92, 1966, pp. 61-88.

7. S. B. Jones, and D. Or, "Microgravity effects on water flow and distribution in unsaturated porous media: Analyses of flight experiment," Water Resources Research, Vol. 35, No. 4, 1999, pp. 929942. 
Public reporting burden for this collection of information is estimated to average 1 hour per response, including the time for reviewing instructions, searching existing data sources, gathering and maintaining the data needed, and completing and reviewing the collection of information. Send comments regarding this burden estimate or any other aspect of this collection of information, including suggestions for reducing this burden, to Washington Headquarters Services, Directorate for Information Operations and Reports, 1215 Jefferson Davis Highway, Suite 1204, Arlington, VA 22202-4302, and to the Office of Management and Budget, Paperwork Reduction Project (0704-0188), Washington, DC 20503.

\begin{tabular}{|l|l|l}
\hline 1. AGENCY USE ONLY (Leave blank) & $\begin{array}{c}\text { 2. REPORT DATE } \\
\text { May } 2006\end{array}$ & $\begin{array}{c}\text { 3. REPORT TYPE AND DATES COVERED } \\
\text { Technical Memorandum }\end{array}$
\end{tabular}

\section{TITLE AND SUBTITLE}

5. FUNDING NUMBERS

Conceptual Design of a Condensing Heat Exchanger for Space Systems Using Porous Media

6. AUTHOR(S)

Mohammad M. Hasan, Lutful I. Khan, Vedha Nayagam, and Ramaswamy Balasubramaniam

7. PERFORMING ORGANIZATION NAME(S) AND ADDRESS(ES)

National Aeronautics and Space Administration

John H. Glenn Research Center at Lewis Field

Cleveland, Ohio 44135-3191

WBS-22-101-13-50

8. PERFORMING ORGANIZATION REPORT NUMBER

E-15464

\section{SPONSORING/MONITORING AGENCY NAME(S) AND ADDRESS(ES)}

10. SPONSORING/MONITORING AGENCY REPORT NUMBER

National Aeronautics and Space Administration

Washington, DC 20546-0001

NASA TM-2006-214130

\section{SUPPLEMENTARY NOTES}

Prepared for the 35th International Conference on Environmental Systems (ICES) cosponsored by SAE, AIAA, AIChE, ASME, and the International ICES Committee, Rome, Italy, July 11-14, 2005. Mohammad M. Hasan, NASA Glenn Research Center, Lutful I. Khan, Cleveland State University, 2121 Euclid Ave., Cleveland, Ohio 44115; Vedha Nayagam and Ramaswamy Baulasubramaniam, National Center for Space Exploration Research, 21000 Brookpark Road, Cleveland, Ohio 44135. Responsible person Mohammad M. Hasan, organization code RUF, 216-433-7494.

\section{2a. DISTRIBUTION/AVAILABILITY STATEMENT}

12b. DISTRIBUTION CODE

Unclassified - Unlimited

Subject Category: 29

Available electronically at http://gltrs.grc.nasa.gov

This publication is available from the NASA Center for AeroSpace Information, 301-621-0390.

13. ABSTRACT (Maximum 200 words)

Condensing heat exchangers are used in many space applications in the thermal and humidity control systems. In the International Space Station (ISS), humidity control is achieved by using a water cooled fin surface over which the moist air condenses, followed by "slurper bars" that take in both the condensate and air into a rotary separator and separates the water from air. The use of a cooled porous substrate as the condensing surface provides and attractive alternative that combines both heat removal as well as liquid/gas separation into a single unit. By selecting the pore sizes of the porous substrate a gravity independent operation may also be possible with this concept. Condensation of vapor into and on the porous surface from the flowing air and the removal of condensate from the porous substrate are the critical processes involved in the proposed concept. This paper describes some preliminary results of the proposed condensate withdrawal process and discusses the on-going design and development work of a porous media based condensing heat exchanger at the NASA Glenn Research Center in collaboration with NASA Johnson Space Center.

\section{SUBJECT TERMS}

Condensing heat exchangers; Porous materials; Capillary flow
15. NUMBER OF PAGES

12

16. PRICE CODE

\begin{tabular}{|c|c|c|}
\hline $\begin{array}{c}\text { 17. SECURITY CLASSIFICATION } \\
\text { OF REPORT } \\
\text { Unclassified }\end{array}$ & $\begin{array}{c}\text { 18. SECURITY CLASSIFICATION } \\
\text { OF THIS PAGE } \\
\text { Unclassified }\end{array}$ & $\begin{array}{c}\text { 19. SECURITY CLASSIFICATION } \\
\text { OF ABSTRACT } \\
\text { Unclassified }\end{array}$ \\
\hline
\end{tabular}

NSN 7540-01-280-5500

Standard Form 298 (Rev. 2-89) 

